\title{
Pengaruh Desain Interior Diffuser Terhadap Peningkatan Performa Diffuser Augmented Wind Turbine (DAWT)
}

\author{
Yiyin Klistafani ${ }^{1, a}$ dan Muh. Iqbal Mukhsen ${ }^{1, b}$ \\ ${ }^{1}$ Teknik Mesin, Politeknik Negeri Ujung Pandang, Jl. Perintis Kemerdekaan KM.10 Tamalanrea, Makassar, 90245, Indonesia \\ ayiyin_klistafani@poliupg.ac.id
}

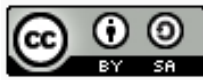

\begin{abstract}
The main objective of numerical simulation in this studies is to determine the effect of diffuser's interior design on increasing the diffuser augmented wind turbine (DAWT) performance by observing wind velocity increment. Numerical studies were carried out using the computational Fluid Dynamics (CFD) method through a two-dimensional steady approach with Ansys Fluent 18.2 and Ansys Workbench 18.2 software. The present studies spesifically investigate the shapes of diffuser, namely flat diffuser and curved diffuser. The studies demonstrate that the curved diffuser generates stronger increment of the wind velocity than flat diffuser (at centreline), which 1.842 times the freestream velocity, while the flat diffuser is only able to increse up to $\mathbf{1 . 7 4 2}$ times the freestream velocity. The curved diffuser shows the highest increment of the average wind velocity along diffuser with the greatest increment of $78.66 \%$ and the flat diffuser is only able to provide average wind velocity increment up to $44.81 \%$. The curved interor of diffuser is able to enlarge the wake area, so the effect of the suction flow entering the diffuser becomes stronger. Therefore, curved diffuser is better to provide DAWT performance improvements.
\end{abstract}

Keywords-CFD; DAWT; diffuser, wind energy, wind turbine.

Abstrak-Tujuan utama dari simulasi numerik pada penelitian ini yaitu untuk mengetahui pengaruh desain interior diffuser terhadap peningkatan performa diffuser augmented wind turbine (DAWT) melalui tinjauan nilai peningkatan kecepatan angin yang mampu dihasilkan. Studi Numerik dilakukan dengan menggunakan metode Computational Fluid Dynamics (CFD) melalui pendekatan steady two-dimensional dengan software Ansys Fluent 18.2 dan Ansys Workbench 18.2. Desain interior diffuser yang digunakan pada penelitian ini yaitu flat diffuser dan curved diffuser. Hasil yang didapat menunjukkan bahwa Curved diffuser mampu meningkatkan kecepatan angin lebih tinggi dibandingkan flat diffuser (pada daerah centreline), sebesar 1,842 kali kecepatan freestream, dimana flat diffuser hanya mampu meningkatkan hingga 1,742 kali kecepatan freestream. Selain itu Curved diffuser mampu memproduksi peningkatan kecepatan rata-rata angin tertinggi sebesar $78,66 \%$, sedangkan Flat diffuser hanya mampu memberikan peningkatan kecepatan rata-rata angin hingga $44,81 \%$. Interior lengkung diffuser mampu memperbesar daerah wake yang terbentuk sehingga efek hisap aliran memasuki diffuser menjadi semakin kuat. Oleh karenanya, curved diffuser lebih mampu memberikan peningkatan performa pada Diffuser Augmented Wind Turbine.

Kata Kunci-CFD; DAWT; diffuser; energi angin; turbin angin.

\section{Pendahuluan}

Energi alternatif sangat menarik untuk dikaji lebih dalam mengingat semakin terbatasnya ketersediaan sumber energi fosil di bumi. Tuntutan kebutuhan energi yang sangat tinggi tidak sebanding dengan ketersediaan sumber daya minyak, sehingga upaya pengembangan pemanfaatan energi alternatif perlu digalakkan.

Indonesia sebagai Negara kepulauan memberikan keuntungan tersendiri dari segi potensi angin. Namun kecepatan angin di daratan Indonesia rata-rata kurang dari 5\%. Data dari BMKG menunjukkan 50 lebih lokasi memiliki kecepatan angin 3-5 m/s, sementara hasil pengukuran LAPAN menunjukkan 30 lebih lokasi dengan kecepatan angin $3-5 \mathrm{~m} / \mathrm{s}$ [1]. Rendahnya kecepatan angin tersebut menjadi salah satu faktor penghambat dalam pemanfaatan teknologi sistem konversi energi angin di Indonesia. Oleh karena itu diperlukan adanya inovasi dalam mengoptimalkan pemanfaatan energi angin di daerah yang memiliki potensi kecepatan angin yang rendah. Salah satu konsep yang sedang berkembang yaitu rekayasa desain geometri diffuser untuk pengembangan DAWT (Diffuser Augmented Wind Turbine).

Pemilihan diffuser sebagai bentuk selubung wind turbine bermula dari penelitian yang dilakukan oleh Ohya yaitu dengan menguji tiga bentuk geometri selubung, nozzle, silinder dan diffuser [2]. Hasil eksperimen menunjukkan bahwa bentuk diffuser 
mampu menghasilkan nilai peningkatan kecepatan relatif angin paling besar dibandingkan dengan geometri yang lain.

Purwanto dan Nasution telah melakukan modifikasi bentuk diffuser dengan interior lengkung untuk mendapatkan performa DAWT yang lebih optimal. Penambahan permukaan lengkung pada interior diffuser mampu meningkatkan kecepatan angin maksimum hingga 30\% [3]. Lipian et al. juga telah melakukan penelitian terkait sensitivitas sudut divergensi diffuser dan ketinggian brim sebagai parameter desain $3 \mathrm{~kW}$ $D A W T$. Hasil yang didapat yaitu penggunaan diffuser $\left(2 \alpha=8^{\circ}\right)$ dengan ketinggian brim sebesar $0.3 D$ mampu menghasilkan peningkatan kecepatan angin sekitar 50\% pada inlet diffuser [4].

Berdasarkan studi yang telah dilakukan sebelumnya, maka sangat menarik untuk dicermati bahwa desain diffuser menjadi salah satu faktor yang menentukan efektifitas penggunaan Diffuser Augmented Wind Turbine (DAWT). Oleh karenanya, sangat penting untuk dilakukan penelitian lebih lanjut secara numerik mengenai pengaruh desain diffuser terhadap peningkatan performa $D A W T$. Tujuan dari penelitian ini yaitu untuk mengetahui pengaruh desain interior diffuser (flat dan curved) terhadap peningkatan performa DAWT dengan fokus terhadap parameter peningkatan kecepatan angin yang dihasilkan.

\section{Metode Penelitian}

Studi Numerik dilakukan dengan menggunakan metode Computational Fluid Dynamics (CFD) dengan software Ansys Fluent 18.2. Prosedur yang dilakukan pada penelitian numerik adalah tahap pre-processing dengan bantuan software Ansys Workbench 18.2, tahap solving dan dilanjutkan dengan tahap post-processing. Studi $C F D$ yang dilakukan dengan fokus utama pada pengembangan aliran di sekitar dua tipe diffuser yang berbeda. Pendekatan steady two-dimensional tetap dilakukan untuk penelitian ini.

\section{A. Tahap Pre-processing}

Tahap awal yang dilakukan adalah mendesain geometri diffuser. Dimensi flat diffuser merujuk pada penelitian Ohya et al. [2] yang juga digunakan acuan oleh Wibowo et al. [5]. Desain kelengkungan diffuser pada curved diffuser disesuaikan dengan dimensi flat diffuser. Ketebalan diffuser yaitu $1,25 \mathrm{~cm}$, mengacu pada studi terbaru yang dilakukan oleh $\mathrm{Hu}$ dan Wang [6], dimana pelat yang digunakan sebanyak sepuluh layer dengan ketebalan masing-pasing 1,25 mm.

Desain diffuser yang disimulasikan dapat dilihat pada gambar 1 dan 2, sedangkan untuk detail dimensi dapat dilihat pada tabel 1. Setelah itu dilakukan grid independence dengan membuat variasi tujuh jenis mesh untuk mendapatkan konfigurasi mesh yang paling sesuai dan mampu memberikan hasil komputasi yang mendekati hasil eksperimen [2].

Penentuan kondisi batas pada simulasi mengacu pada penelitian terdahulu [2, 7]. Kondisi batas yang ditetapkan pada simulasi dapat dilihat pada gambar 3 .

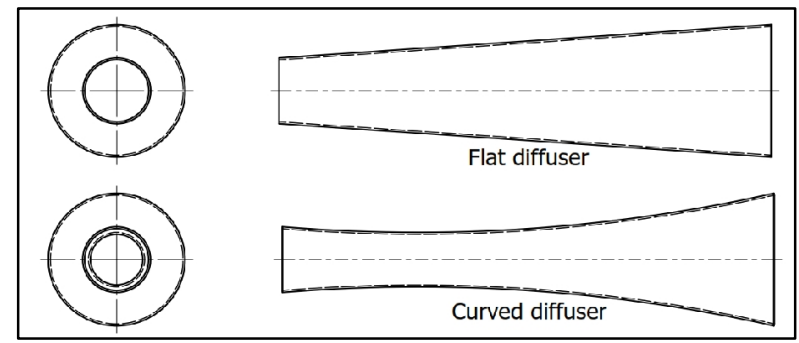

Gambar 1. Desain Interior Diffuser

Tabel 1. Dimensi Geometri Diffuser

\begin{tabular}{|l|c|c|}
\hline Spesifikasi & $\begin{array}{c}\text { Flat } \\
\text { Diffuser }\end{array}$ & $\begin{array}{c}\text { Curved } \\
\text { Diffuser }\end{array}$ \\
\hline Diameter inlet $(D)$ & $40 \mathrm{~cm}$ & $40 \mathrm{~cm}$ \\
\hline Panjang diffuser, $(L)$ & $308 \mathrm{~cm}$ & $308 \mathrm{~cm}$ \\
\hline Panjang inlet shroud, $(l)$ & - & - \\
\hline Ketebalan diffuser $(t)$ & $1,25 \mathrm{~cm}$ & $1,25 \mathrm{~cm}$ \\
\hline Sudut bukaan, $\alpha\left(^{\circ}\right)$ & $4^{\circ}$ & $4^{\circ}$ \\
\hline Jari-jari kelengkungan, $r$ & - & $1000 \mathrm{~cm}$ \\
\hline
\end{tabular}

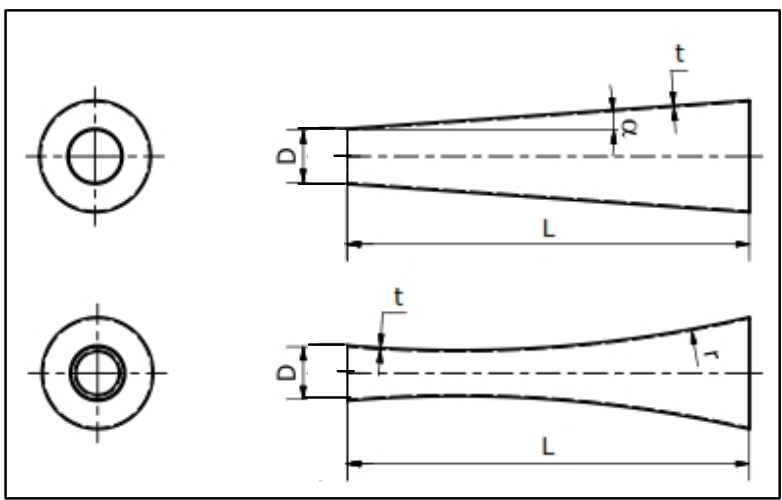

Gambar 2. Detail dimensi flat diffuser dan curved diffuser

\section{B. Tahap Solving}

Komputasi numerik dilakukan dengan menggunakan software ANSYS Fluent 18.2. Aliran diasumsikan steady dan incompressible. Hal tersebut sangat beralasan karena turbin angin beroperasi pada kecepatan yang lebih rendah dari pada kecepatan suara.

Pada langkah penentuan viscous model, Shear Stress Transport (SST) $k$ - $\omega$ dipilih sebagai turbulence model yang terdiri atas dua persamaan dasar menurut Menter 
[8]. Model tersebut terdiri atas kombinasi dari model standard $k-\varepsilon$ [9] di daerah freestream dan Wilcox $k-\omega$ model [10] untuk aliran di dekat dinding. SST $k-\omega$ merupakan model turbulensi yang baik dalam hal memprediksi aliran dengan pengaruh adverse pressure gradient yang kuat sebagaimana telah digunakan pada simulasi numerik terdahulu $\mathrm{Hu}$ dan Wang [6], Bangga dan Sasongko [11], Bangga et al. [12], Pape and Lecanu [13], Sørensen et al [14], Weihing et al. [15], Jost et al [16], dan Klistafani [17, 18].

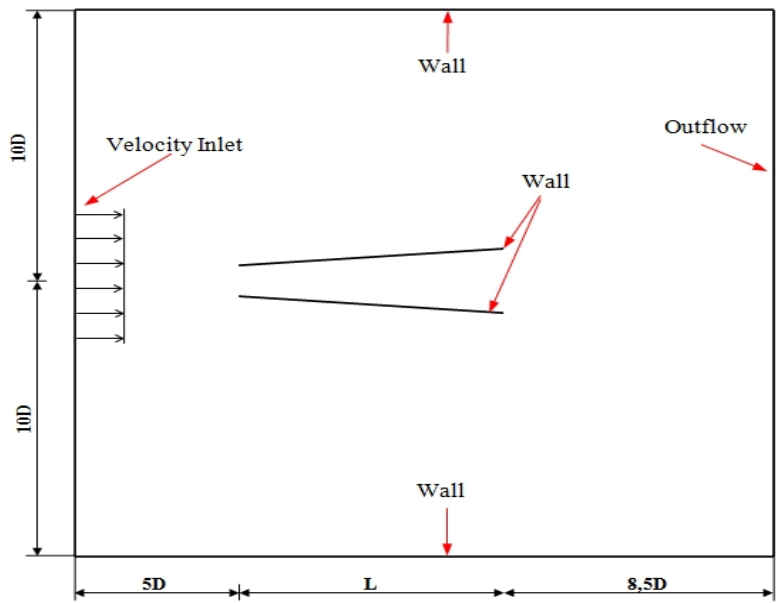

Gambar 3. Kondisi batas simulasi

Penetapan jenis material yang akan digunakaan yaitu udara dengan density $(\rho) 1,225 \mathrm{~kg} / \mathrm{m}^{3}$ dan viskositas $(\mu)$ $1,7894 \times 10^{-5} \mathrm{~kg} / \mathrm{m}$.s. Kondisi batas yang ditentukan pada daerah inlet yaitu velocity inlet. Bilangan Reynolds, $R e=1,36 \times 10^{5}$ berdasarkan nilai kecepatan angin sebesar $5 \mathrm{~m} / \mathrm{s}[2,5]$. Nilai intensitas turbulen yang ditentukan yaitu 3\%. Sedangkan outlet adalah outflow. Detail boundary condition seperti yang terlihat pada tabel 3.2. Solution pada penelitian ini akan menggunakan discretization second order untuk pressure, second-order upwind untuk momentum, turbulence kinetic energy dan turbulence dissipation rate. Kriteria konvergensi ditetapkan sebesar $10^{-6}$ dengan batas iterasi sampai dengan 10.000 iterasi.

B. Tahap Post-Processing

Post-processing merupakan tahapan mengekstrak hasil komputasi yang telah diperoleh. Hasil tersebut dapat berupa raw data ataupun hasil visualisasi. Raw data yang diekstrak diantaranya plot $x-y$ kecepatan aliran dan tekanan statis di sepanjang midline (cetreline) diffuser, dan kecepatan aliran di setiap section $(x / L)$. Adapun hasil visualisasi yang di-export untuk dijadikan bahan kajian adalah kontur kecepatan dan vektor kecepatan

\section{Hasil dan Pembahasan}

\section{III.1 Streamwise flow velocity}

Distribusi peningkatan kecepatan angin disepanjang sumbu axial diffuser hasil ekperimen [2] dan numerik dapat dilihat pada gambar 4. Perbandingan distribusi streamwise flow velocity dilakukan guna memvalidasi hasil komputasi numerik dengan hasil eksperimen. Data peningkatan kecepatan angin yang dibandingkan adalah data untuk flat diffuser, dimana spesifikasi dimensi flat diffuser pada simulasi mengacu pada spesifikasi diffuser yang digunakan oleh Ohya et al [2].

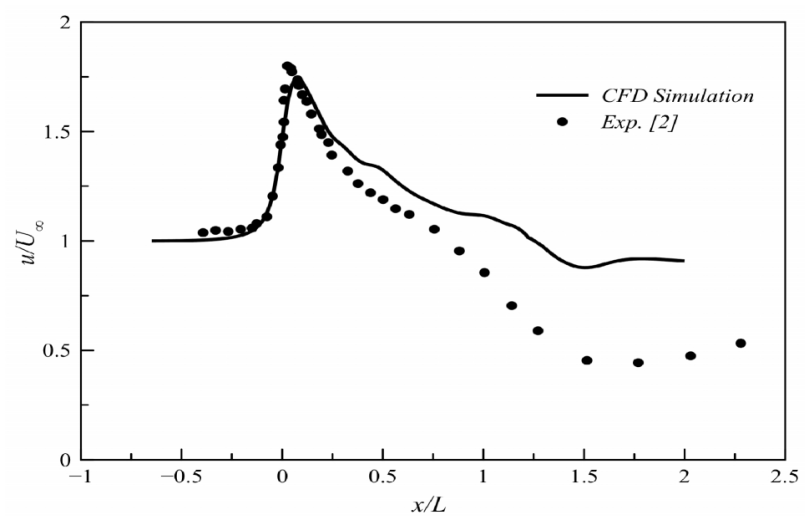

Gambar 4. Perbandingan distribusi streamwise flow velocity disepanjang sumbu axial (centreline) diffuser hasil eksperimen [2] dan numerik

Terlihat pada gambar 4 bahwa hasil simulasi yang telah dilakukan memiliki kesamaan dengan hasil eksperimen [2], terutama untuk peningkatan kecepatan angin pada daerah upstream hingga outlet diffuser. Peningkatan kecepatan tertinggi pada hasil eksperimen mencapai 1,795 kali kecepatan freestream $(5 \mathrm{~m} / \mathrm{s})$, sedangkan pada hasil numerik peningkatan kecepatan angin tertinggi mencapai 1,742 kali. Hal ini mengindikasikan bahwa selisih prediksi numerik dengan eksperimen dalam hal peningkatan kecepatan angin tertinggi berkisar $2.95 \%$.

Perbandingan distribusi peningkatan kecepatan angin yang dihasilkan flat diffuser dan curved diffuser pada centreline diffuser dapat dilihat pada gambar 5 . Curved diffuser mampu meningkatkan kecepatan angin lebih tinggi dibandingkan flat diffuser, yakni hingga 1,842 kali $(x / L=0,285)$ kecepatan freestream, dimana flat diffuser hanya mampu meningkatkan hingga 1,742 kali $(x / L=0,077)$ kecepatan freestream. Namun peningkatan kecepatan angin pada daerah centreline diffuser sejatinya belum mampu mewakili kondisi aktual dari keseluruhan kecepatan angin di dalam diffuser. Oleh karenanya pada penelitian kali ini juga dikaji tentang peningkatan kecepatan rata-rata yang 
dihasilkan oleh diffuser di setiap section sepanjang arah axial, seperti yang terlihat pada gambar 6 .

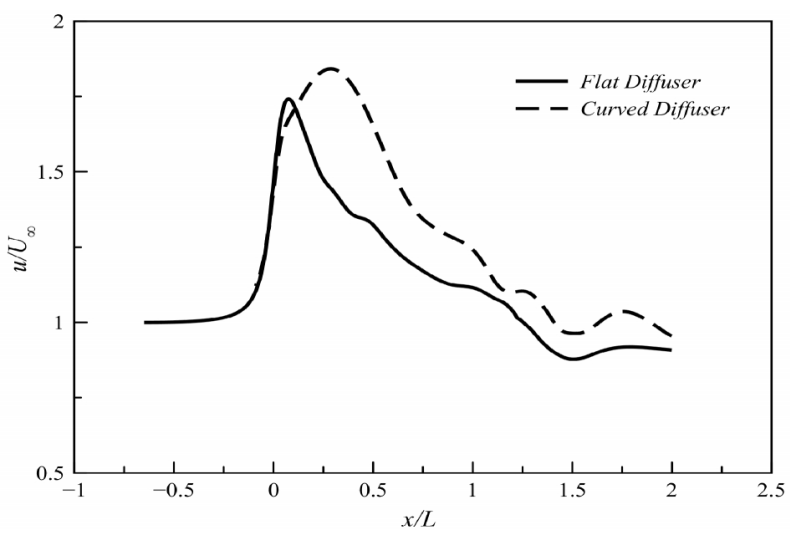

Gambar 5. Distribusi streamwise flow velocity disepanjang sumbu axial (centreline) diffuser untuk flat diffuser dan curved diffuser

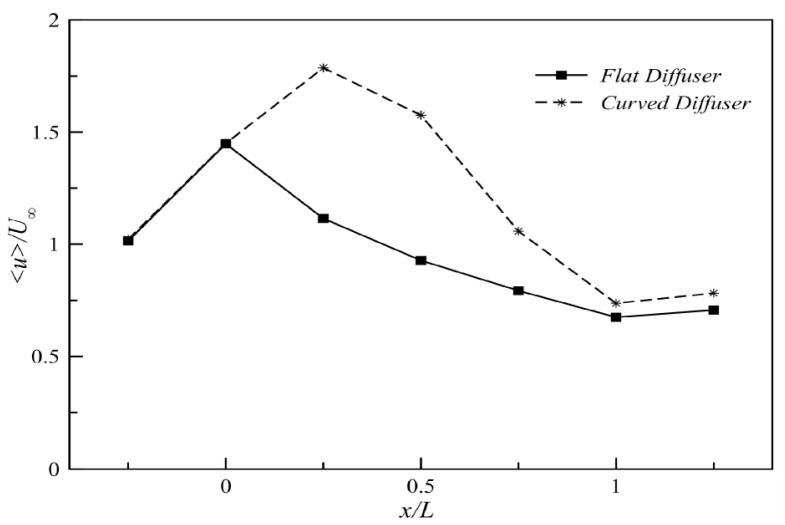

Gambar 6. Distribusi peningkatan kecepatan angin rata-rata disepanjang sumbu axial (centreline) diffuser untuk flat diffuser dan curved diffuser

Terlihat pada gambar 6 bahwa tidak ada perbedaan peningkatan kecepatan rata-rata yang dihasilkan oleh flat diffuser dengan curved diffuser pada daerah upstream hingga inlet diffuser $(x / L=0)$. Selisih peningkatan kecepatan rata-rata angin sangat signifikan disepanjang diffuser section, sedangkan pada daerah downstream selisih tersebut mulai mengecil kembali.

Curved diffuser mampu memproduksi peningkatan kecepatan rata-rata angin tertinggi yaitu 78,66\% dengan kecepatan rata-rata maksimum $8,93 \mathrm{~m} / \mathrm{s}$ pada $x / L=$ 0,77 . Hal ini tentunya berbeda dengan peningkatan kecepatan angin pada daerah centreline curved diffuser (gambar 5), dimana kecepatan maksimum yang dihasilkan yaitu $9,21 \mathrm{~m} / \mathrm{s}$.

Flat diffuser hanya mampu memberikan peningkatan kecepatan rata-rata angin hingga $44,81 \%$ dengan kecepatan angin rata-rata tertinggi pada section $x / L=0$ sebesar 7,24 m/s. Jika hanya meninjau kecepatan pada daerah centreline, maka flat diffuser mampu meningkatkan kecepatan angin sebesar 74,2\% dengan kecepatan tertinggi sebesar $8.71 \mathrm{~m} / \mathrm{s}$ (gambar 5). Berdasarkan penjelasan tersebut maka dapat disimpulkan bahwa peningkatan kecepatan angin pada daerah centreline tidak mampu mewakili kondisi keseluruhan kecepatan angin di dalam diffuser pada setiap section.

\section{III.2 Coefficient Pressure}

Perbandingan kuantitatif antara hasil simulasi dengan eksperimen yang telah dilakukan Ohya et al. [2] dapat dilihat juga pada gambar 7, yaitu perbandingan distribusi coefficient pressure pada flat diffuser. Hasil komputasi menunjukkan persamaan hasil dengan eksperimen pada daerah upstream hingga inlet diffuser $(x / L=0)$. Selisih nilai $C p$ terendah diantara keduanya yaitu 2,67\%, dimana $C p$ terendah hasil eksperimen yaitu $-1,855$ sedangkan $C p$ terendah hasil numerik yaitu $-1,904$.

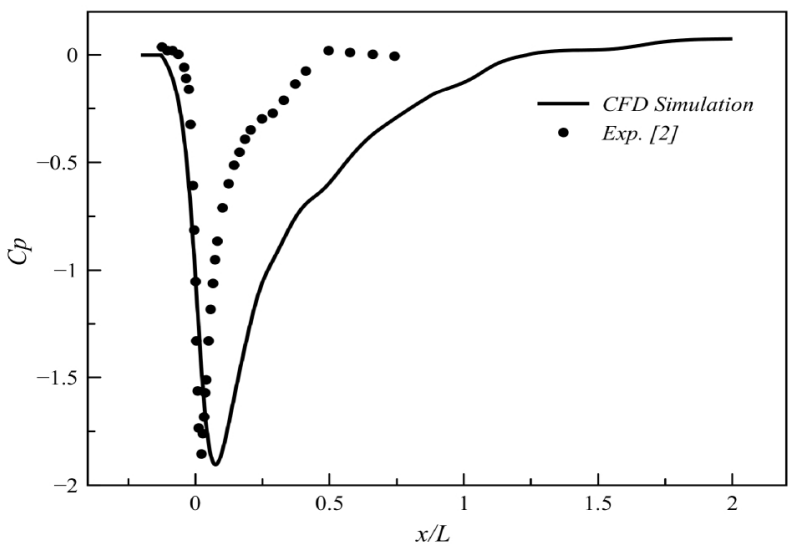

Gambar 7. Perbandingan distribusi coefficient pressure disepanjang sumbu axial (centreline) diffuser hasil eksperimen [2] dan numerik

Distribusi coefficient pressure flat diffuser dan curved diffuser dapat dilihat pada gambar 8 . Tidak ada perbedaan nilai $C p$ yang signifikan antara flat diffuser dan curved diffuser pada daerah upstream hingga inlet diffuser $(x / L=0)$. Namun pada daerah di sepanjang diffuser hingga downstream, nilai $C p$ yang dihasilkan oleh curved diffuser $(-2,344)$ lebih rendah dibandingkan dengan nilai $C p$ yang dihasilkan oleh flat diffuser (1,904). Semakin rendah pressure yang dihasilkan maka semakin tinggi potensi peningkatan kecepatan angin yang dihasilkan, hal tersebut sesuai dengan Hukum Bernoulli. Oleh karenanya kajian coefficient pressure memberikan gambaran yang sama dengan distribusi streamwise flow velocity (gambar 5), dimana curved diffuser memiliki performa yang lebih baik 
dibandingkan dengan flat diffuser karena mampu mengingkatkan kecepatan angin lebih optimal.

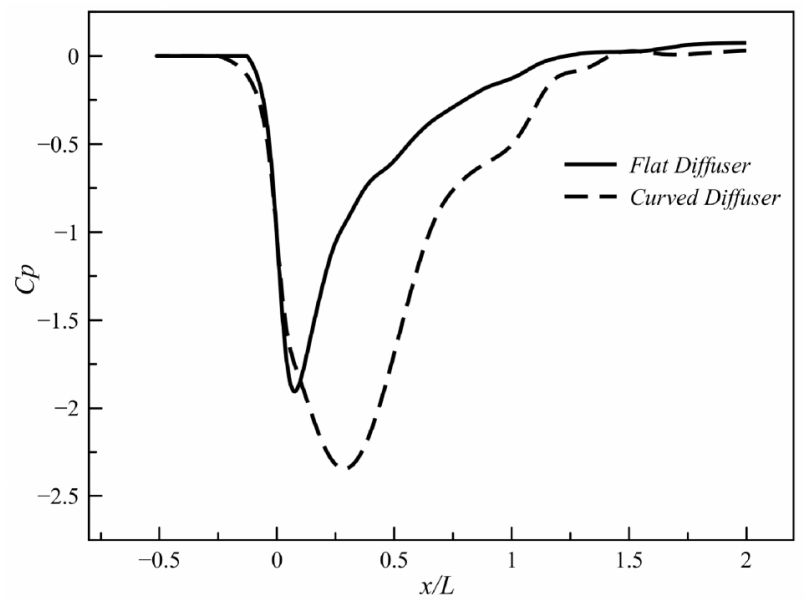

Gambar 8. Distribusi coefficient pressure disepanjang sumbu axial (centreline) diffuser untuk flat diffuser dan curved diffuser

\section{III.3 Kontur dan Vektor Kecepatan}

Kontur kecepatan dan vektor kecepatan untuk flat diffuser dan curved diffuser dapat dilihat pada gambar 9 dan 10. Pada gambar terlihat bahwa kontur kecepatan pada curved diffuser lebih didominasi dengan warna merah di dalam diffuser. Hal ini menunjukkan bahwa curved diffuser mampu menghasilkan kecepatan fluida yang tinggi di daerah setelah sisi inlet diffuser dan kecepatan menurun perlahan-lahan (ditunjukkan dengan gradasi warna jingga ke hijau) hingga daerah downstream.

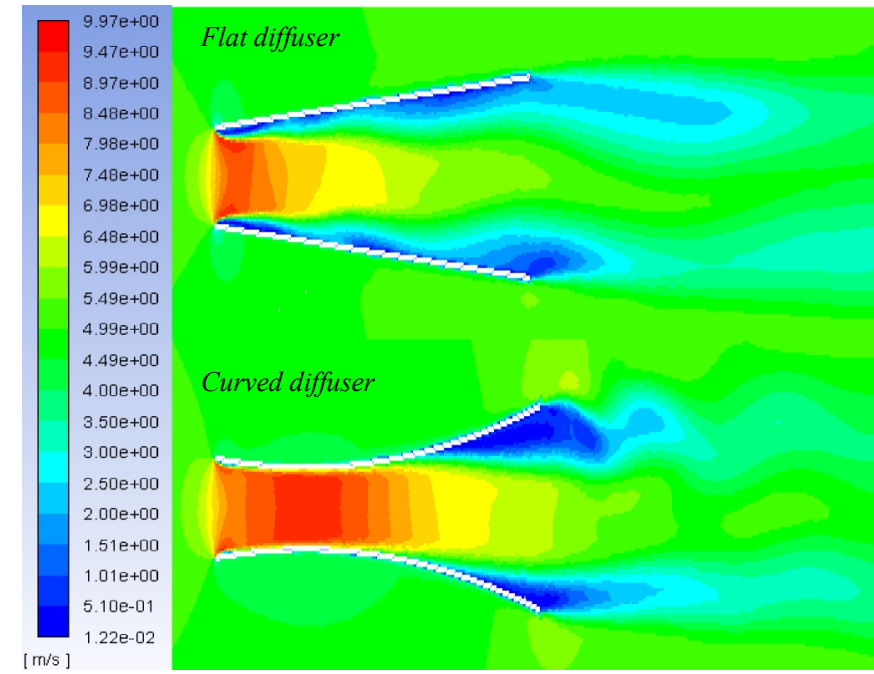

Gambar 9. Kontur Kecepatan untuk flat diffuser dan curved diffuser (velocity magnitude, $\mathrm{m} / \mathrm{s}$ )

Selain itu kontur kecepatan pada daerah dekat dinding di sekitar outlet diffuser hingga downstream sangat menarik untuk dikaji. Pada daerah tersebut untuk flat diffuser, vortex (zona yang berwarna biru tua) yang terbentuk sangatlah kecil dibandingkan dengan curved diffuser. Vortisiti yang besar pada bagian belakang curved diffuser mengakibatkan aliran fluida pada sisi upstream dihisap dengan cepat hingga masuk ke diffuser. Efek hisap dari vortex downstream mampu menghasilkan dampak positif dalam meningkatkan kualitas kecepatan angin di dalam diffuser [19]. Hal ini membuktikan bahwa interior lengkung diffuser mampu memperbesar daerah wake yang terbentuk sehingga efek hisap aliran memasuki diffuser juga semakin kuat. Fenomena tersebut didukung juga dengan bukti tampilan vektor kecepatan pada gambar 10 .

Pada gambar 10 terlihat jelas adanya back flow di dekat wall outlet curved diffuser. Hal ini menandakan vortex telah terbentuk pada daerah tersebut, sehingga mampu meningkatkan efek hisap fluida ke dalam curved diffuser. Oleh karenanya curved diffuser mampu memproduksi peningkatan angin lebih baik daripada flat diffuser. Hal tersebut sesuai dengan

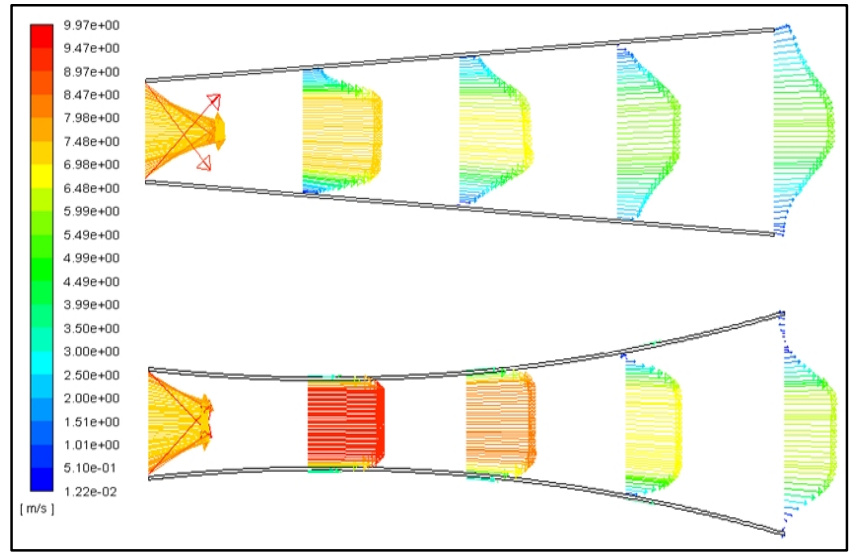

Gambar 10. Vektor kecepatan untuk flat diffuser dan curved diffuser (velocity magnitude, $\mathrm{m} / \mathrm{s}$ )

\section{Kesimpulan}

Beberapa kesimpulan yang didapat dari penelitian ini yaitu sebagai berikut:

- Hasil simulasi numerik yaitu streamwise flow velocity dan coefficient pressure yang didapatkan mendekati hasil eksperimen, walupun terdapat perbedaan pada daerah wake.

- Selisih prediksi numerik dengan eksperimen dalam hal peningkatan kecepatan angin tertinggi berkisar $2.95 \%$. Sedangkan selisih nilai $C p$ terendah diantara keduanya yaitu $2,67 \%$.

- Curved diffuser mampu meningkatkan kecepatan angin lebih tinggi dibandingkan flat diffuser, yakni hingga 1,842 kali $(x / L=0,285)$ kecepatan 
freestream, dimana flat diffuser hanya mampu meningkatkan hingga 1,742 kali $(x / L=0,077)$ kecepatan freestream

- Curved diffuser mampu memproduksi peningkatan kecepatan rata-rata angin tertinggi yaitu $78,66 \%$ dengan kecepatan rata-rata maksimum $8,93 \mathrm{~m} / \mathrm{s}$ pada $x / L=0,77$. Sedangkan Flat diffuser hanya mampu memberikan peningkatan kecepatan ratarata angin hingga 44,81\% dengan kecepatan angin rata-rata tertinggi pada section $x / L=0$ sebesar 7,24 $\mathrm{m} / \mathrm{s}$

- Peningkatan kecepatan angin pada daerah centreline tidak mampu mewakili kondisi keseluruhan kecepatan angin di dalam diffuser pada setiap section.

- Nilai $C p$ yang dihasilkan oleh curved diffuser sebesar -2,344, lebih rendah dibandingkan dengan nilai $C p$ yang dihasilkan oleh flat diffuser sebesar 1,904 .

- Interior lengkung diffuser mampu memperbesar daerah wake yang terbentuk sehingga efek hisap aliran memasuki diffuser juga semakin kuat. Oleh karenanya, curved diffuser lebih mampu memberikan peningkatan performa pada Diffuser Augmented Wind Turbine, karena dapat meningkatkan kecepatan angin lebih optimal.

\section{Ucapan Terima Kasih}

Kami ucapkan terima kasih kepada Direktorat Riset dan Pengabdian kepada Masyarakat, Direktorat Jenderal Penguatan Riset dan Pengembangan, Kementerian Riset, Teknologi, dan Pendidikan tinggi Republik Indonesia atas bantuan hibah dana untuk kegiatan penelitian ini sehingga kegiatan penelitian dapat terlaksana dengan baik.

\section{Daftar Pustaka}

[1] Syahrul, "Prospek pemanfaatan energi angin sebagai energi alternatif di daerah pedesaan," Media Elektrik, vol.3 no.2, hal.140-144, 2008.

[2] Y. Ohya, T. Karasudani, A. Sakurai, K. Abe, and M. Inoue, "Development of s shrouded wind turbine with a flanged diffuser," Journal of wind engineering and industrial aerodynamics, 96, pp. 524-539, 2008.

[3] D.W. Purwanto dan A.M.T. Nasution, "Interior lengkung diffuser untuk peningkatan performansi diffuser augmented wind turbine (DAWT)," Prosiding seminar nasional energi terbarukan Indonesia I, 2010.

[4] M. Lipian, M. Karczewski, and K. Olasek, "Sensitivity study of diffuser angle and brim height parameters for the design of $3 \mathrm{~kW}$ diffuser augmented wind turbine," Open engineering, 5, pp. $280-286,2015$.
[5] A.T.H. Wibowo, R.A. Wahyuono, dan G. Nugroho, "Studi numerik pengaruh geometri dan desain diffuser untuk peningkatan kinerja DAWT (diffuser augmented wind turbine)," Jurnal Teknik Mesin, vol. 14 no.2, hal.90-96, ISSN 1410-9867, 2013.

[6] J. Hu, W. Wang, "Upgrading a shrouded wind turbine with a self adaptive flanged diffuser," Energies, 8, pp.5319-5337, 2015 .

[7] K. Abe and Y. Ohya, "An investigation of flow fields around flanged diffusers using CFD," Journal of wind engineering and industrial aerodynamics, 92, pp.315-330, 2004.

[8] F.R. Menter, "Two-equation eddy-viscosity turbulence models for engineering applications," AIAA journal, 32(8), pp.1598-1605, 1994.

[9] B.E. Launder, D.B. Spalding, "Mathematical models of turbulence," Academic press, 1972.

[10] D.C. Wilcox, "Turbulance modelling fo CFD". DCW Industries, 1993.

[11] G. Bangga and H. Sasongko, "Dynamic stall prediction of a pitching airfoil using an adjusted two-equation URANS turbulence model," Journal of Applied Fluid Mechanics, 10(1), pp.1-10, 2017.

[12] G. Bangga, T. Kusumadewi, G. Hutomo, A. Sabila, T. Syawitri, H. Setiadi, M. Faisal, R. Wiranegara, Y. Hendranata, D. Lastomo, L. Putra, "Improving a two-equation eddyviscosity turbulence model to predict the aerodynamic performance of thick wind turbine airfoils," Journal of Physics: Conference Series, 974(1), 012019, 2018.

[13] A.L. Pape, and J. Lecanu, "3D Navier-Stokes computations of a stall regulated wind turbine," Wind Energy, 7(4), pp.309324, 2004.

[14] N.N. Sørensen, J.A. Michelsen, S. Schreck, "Navier-Stokes predictions of the NREL phase VI rotor in the NASA Ames $80 \mathrm{ft} \times 120 \mathrm{ft}$ wind tunnel," Wind Energy, 5(2-3), pp.151-169, 2002.

[15] P. Weihing, J. Letzgus, G. Bangga, T. Lutz, and E. Krämer, "Hybrid RANS/LES Capabilities of the Flow Solver FLOWer-Application to Flow Around Wind Turbines," In Symposium on Hybrid RANS-LES Methods Springer, Cham, pp.369-380, 2016.

[16] E. Jost, A. Fischer, G. Bangga, T. Lutz, E. Krämer, "An investigation of unsteady 3-D effects on trailing edge flaps," Wind Energy Science, 2(1), pp.241-256, 2017.

[17] Y. Klistafani, "Studi numerik steady RANS aliran fluida di dalam asymmetric diffuser," Journal INTEK, vol. 4 (1), pp.20-26, April 2017.

[18] Y. Klistafani, "Karakteristik aliran fluida di dalam asymmetric diffuser dengan penambahan vortex generator," Journal INTEK, vol. 5 (1), pp.21-26, 2018.

[19] Y. Klistafani, M.I. Mukhsen, and G. Bangga "Assessment of Various Diffuser Structures to Improve the PowerProduction of a Wind Turbine Rotor," Technische Mechanik, vol. 38, pp.256-266, 2018. 